\title{
Aprendizagem científica no trabalho ${ }^{+*}$
}

Sergio de Mello Arruda ${ }^{1}$

Departamento de Física - UEL

Marinez Meneghello Passos ${ }^{2}$

Departamento de Matemática - UEL

Edelaine Cristina de Andrade 3

Marcus Vinícius Martinez Piratelo ${ }^{4}$

Programa em Ensino de Ciências e Educação Matemática - UEL

Londrina - PR

\section{Resumo}

O presente artigo trata da aprendizagem científica no trabalho. A pesquisa é parte de um projeto mais amplo de avançar na compreensão da aprendizagem informal nas diversas configurações em que ela pode ser encontrada. Foram realizadas duas tomadas de dados, por meio de entrevistas semiestruturadas com cinco trabalhadores da construção civil e com dois técnicos em conserto de refrigeradores. Para a organização e análise dos dados foram utilizados os procedimentos da Análise Textual Discursiva, com categorias a priori estruturadas de acordo com as dimensões da aprendizagem de Illeris (2013). Nas análises empregamos a teoria social da aprendizagem de Wenger (2013) e uma analogia entre os saberes do trabalho e os saberes docentes de Tardif (2002). Os resultados apontam que: os saberes construídos pelos sujeitos são constituídos como um conjunto de representações a partir das quais eles interpretam, compreendem e resolvem os problemas de sua prática cotidiana; tais saberes foram construídos porque são úteis e necessários para a prática da profissão; a aprendizagem de tais saberes se deu principal-

\footnotetext{
${ }^{+}$Scientific Learning at Work

* Recebido: agosto de 2014. Aceito: setembro de 2014.

1 E-mail: renop@uel.br - Com o apoio do CNPq.

2 E-mail: marinezmp@ sercomtel.com.br - Com o apoio da Fundação Araucária.

3 E-mail: edelaineandrade@bol.com.br - Com o apoio da Capes.

${ }^{4}$ E-mail: mvmpiratelo@yahoo.com.br-Com o apoio da Capes.
} 
mente com o auxílio dos colegas mais experientes da comunidade de que faziam parte.

Palavras-chave: Aprendizagem no trabalho; Aprendizagem informal; Teoria social de Wenger; Saberes docentes.

\begin{abstract}
This paper deals with the scientific learning at work. The research is part of a broader project to advance the understanding of informal learning in various settings in which it can be found. The data were collected through semi-structured interviews with five building workers and two technicians in repairing refrigerators. For the organization of data, the procedures of Textual Discourse Analysis were used, with categories structured a priori according to the dimensions of learning by Illeris (2013). The social learning theory by Wenger (2013) and an analogy between worker's knowledge and teacher's knowledge by Tardif (2002) were used in the analysis. The results showed that: the knowledge constructed by the subjects are constituted as a set of representations from which they interpret, understand and solve problems in their daily practice; such knowledge were built because they are useful and necessary for the practice of the profession; the learning of such knowledge occurred, mainly, with help of more experienced colleagues in the community which they were part.
\end{abstract}

Keywords: Learning at work; Informal learning; Social learning theory of Wenger; Teacher's knowledge.

\title{
Introdução
}

O presente artigo trata da aprendizagem científica no trabalho. Faz parte de um projeto mais amplo de avançar na compreensão da aprendizagem informal nas diversas configurações em que ela pode ser encontrada. A aprendizagem no trabalho vem sendo investigada há mais de vinte anos (BILLETT, 2001, p. 2). De acordo com Dierking (2005), "o local de trabalho é onde aprendemos as habilidades necessárias para a realização de um trabalho produtivo" (DIERKING, 2005, p. 148). A princípio, devemos distinguir entre a aprendizagem para o trabalho (educação e treinamento profissional), no trabalho (aprendizagem decorrente da prática profissional) e por meio do trabalho (estágios) (SEAGRAVES, 1996, citado por HYLAND, 2010, p. 61). Neste artigo apresentamos resultados de reflexões desenvolvidas sobre a aprendizagem no trabalho, referentes às profissões de: trabalhador da construção civil, que 
exige alguns saberes matemáticos para ser exercida; a de técnicos em conserto de refrigeradores, no que diz respeito aos saberes da Física.

A aprendizagem no trabalho, ou nos locais de trabalho, ou ainda em decorrência das tarefas próprias inerentes à realização do mesmo, pode ser considerada como um caso de $a$ prendizagem ao longo da vida (ALV) ou lifelong learning (como é denominada em língua inglesa). Embora venha sendo utilizada há bastante tempo e em diversos contextos, o termo ALV é considerado mal definido (ALHEIT; DALSIEN, 2006) e seu significado não é muito claro (ASPIN; CHAPMAN, 2010, p. 19). O conceito aparece na literatura como sinônimo de diversos outros termos como educação profissional, educação técnica, educação permanente, educação continuada, educação de adultos etc. (ASPIN; CHAPMAN, 2010, p. 19).

Bagnall aponta que a ALV tem sido utilizada na literatura de forma variada para denotar a educação como: (i) a preparação do indivíduo para o gerenciamento de sua vida adulta; (ii) a distribuição da educação através do tempo de vida de um sujeito; (iii) a função educativa da totalidade da vida de uma pessoa; e (iv) a identificação da educação com a totalidade da vida de uma pessoa (BAGNALL, 1990, p. 1).

Neste artigo, utilizaremos o termo ALV, conforme apresentado no Learning Science in Informal Environments ${ }^{5}$ (NRC, 2009), uma publicação que tem balizado nossas pesquisas sobre aprendizagem informal nos últimos cinco anos (ARRUDA et al., 2013):

\begin{abstract}
A aprendizagem ao longo da vida é uma noção familiar. Ela se refere à aquisição de competências e atitudes fundamentais e à facilidade de utilizar efetivamente a informação ao longo do curso da vida, reconhecendo que as necessidades de desenvolvimento e o interesse variam em diferentes estágios da vida. Geralmente, os aprendizes preferem procurar informação e adquirir maneiras de fazer as coisas porque eles estão motivados a fazer isso em função de interesses, necessidades, curiosidades, prazer e sentem que têm talento que se alinham com certos tipos de tarefas e desafios (NRC, 2009, p. 28).
\end{abstract}

Assim sendo, a ALV pode ser identificada como uma aprendizagem por livre escolha (DIERKING, 2005), um campo de pesquisa relacionado à aprendizagem informal, cujos resultados foram parcialmente incorporados aos dados apresentados no NRC (2009, p. 21 e 32).

Em um relatório da Comissão Europeia, que temos utilizado com frequência em nossos trabalhos (VERONA; MORI; ARRUDA, 2008; ALVES; PASSOS; ARRUDA, 2010; ARRUDA et al., 2013), a aprendizagem informal (AI) foi assim definida:

Aprendizado Informal: resulta das atividades do dia a dia, relacionadas ao trabalho, família ou lazer. Não é estruturada (em termos de objetivos, tempo e suporte à aprendizagem) e normalmente não leva a uma certificação. O aprendizado informal

\footnotetext{
5 Trata-se de um relatório do National Research Council dos Estados Unidos da América.
} 
pode ser intencional, mas na maioria das vezes é não intencional ou incidental (EUROPEAN COMMISSION, 2001, p. 32-33).

As experiências relacionadas à AI são caracterizadas no NRC 2009 como:

[...] motivadoras, guiadas pelo interesse do aprendiz, voluntárias, pessoais, contínuas, contextualmente relevantes, colaborativas, não lineares e abertas [...]. Os participantes [das experiências de aprendizagem científica informal] incluem aprendizes de todas as idades, culturas, níveis socioeconômicos e habilidades [...] os quais podem explorar experiências em casa, no trabalho, em organizações comunitárias ou em qualquer lugar (NRC, 2009, p. 11).

O que chama a atenção nas duas citações anteriores, é que a aprendizagem no trabalho é tomada como um caso da AI. Billett aponta que embora haja esta tendência de se considerar a aprendizagem no trabalho como AI, isto traz alguma ambiguidade ao conceito, podendo, inclusive, induzir algum ceticismo com relação à qualidade da aprendizagem no ambiente de trabalho, o que é refutado por esse autor (BILLETT, 2001, p. 14).

De fato, o NRC chama a atenção para algumas diferenças entre a aprendizagem relacionada ao ambiente de trabalho e aquelas classificadas como nitidamente informais, embora não negue que haja alguma intersecção e semelhanças entre todas elas, por ocorrerem no dia a dia. No que diz respeito ao trabalho, o envolvimento do aprendiz não é totalmente por livre escolha (NRC, 2009, p. 42), o que é uma característica essencial da AI. Além disso, no aprendizado no trabalho sempre se utilizam testes ou outros tipos de procedimentos para documentar as avaliações (NRC, 2009, p. 54), o que, segundo alguns autores, não faz parte da educação informal.

Em síntese, embora o aprendizado científico no trabalho seja reconhecido como perfeitamente possível e possa ser considerado como um "ambiente de aprendizagem legítimo e efetivo" (BILLETT, 2001, p. 14), o NRC faz questão de separar este ambiente de aprendizado - que é mais organizado e estruturado - dos demais ambientes de aprendizagem encontrados no dia a dia, como a família, momentos de lazer etc. (NRC, 2009, p. 94). De fato, para ser efetivo, o ambiente de trabalho deve ser estruturado, organizado: não se aprende no trabalho apenas fazendo, sem ajuda de alguém mais experiente (BILLETT, 2001, p. 7):

Aprender e trabalhar são interdependentes. Nós aprendemos constantemente ao nos envolvermos em atividades cotidianas conscientemente direcionadas a um objetivo - de fato, assim como pensamos e agimos, aprendemos. Entretanto, a qualidade deste aprendizado deve depender: (a) do tipo de atividades que os indivíduos se envolvem; (b) do seu acesso a contribuições de fatores situacionais; e (c) de como os indivíduos se envolvem, interagem e constroem, de forma interpretativa, o conhecimento nessas situações (BILLETT, 2001, p. 21). 


\section{As questões de pesquisa}

O problema de pesquisa em que estamos interessados é semelhante ao considerado por Billett (2001, p. 2): como as pessoas aprendem ciência nos locais de trabalho? Certamente que nem todo trabalho pode ser considerado como uma configuração propícia para o aprendizado científico. Mas é inegável que algumas profissões exigem diversos conhecimentos que ou são parte do conhecimento científico ou mantêm com ele estreita relação. Nosso problema consiste, portanto, em verificar como as demandas da prática profissional, em alguns casos, levam o sujeito a aprender ciência.

No entanto, precisamos lembrar, em primeiro lugar, que a ciência pode ser vista como conteúdo ou como processo:

A ciência é tanto um corpo de conhecimento que representa o entendimento atual dos sistemas naturais quanto o processo pelo qual esse corpo de conhecimento foi estabelecido e está sendo continuamente ampliado, refinado e revisado (NRC, 2007 p. 2.1)

Se isso é assim, na aprendizagem da ciência é preciso levar em consideração tanto um aspecto quanto o outro.

Também situamos esse trabalho dentro da perspectiva trazida por Illeris (2013), que apresenta uma definição ampla de aprendizagem como:

[...] qualquer processo que, em organismos vivos, leve a uma mudança permanente em capacidades e que não se deva unicamente ao amadurecimento biológico ou ao envelhecimento (ILLERIS, 2013, p. 16).

Para Illeris, a aprendizagem integraria dois processos: um externo, que envolve a interação do sujeito com o ambiente (social, cultural ou material); e um interno, que diz respeito ao processo de elaboração e aquisição do conhecimento e que envolveria duas funções psicológicas: "A função de administrar o conteúdo da aprendizagem e a função de incentivo e de prover e direcionar a energia mental necessária que move o processo" (ILLERIS, 2013, p. 17).

A aprendizagem também apresentaria três dimensões:

a. A dimensão do conteúdo diz respeito àquilo que é aprendido - conhecimento, habilidades, opiniões, insights, significados, posturas, valores, modos de agir, métodos, estratégias etc. podem estar envolvidas como conteúdo da aprendizagem e contribuir para construir a compreensão e a capacidade do aprendiz [...] para lidar com os desafios da vida prática e, assim, desenvolver uma funcionalidade pessoal geral.

b. A dimensão do incentivo proporciona e direciona a energia mental necessária para o processo de aprendizagem. Ela compreende elementos como sentimentos, emoções, motivação e volição. Sua função, em última analise, é garantir o equilíbrio mental contínuo do indivíduo e, assim, desenvolver simultaneamente uma sensibilidade pessoal. 
c. A dimensão da interação propicia os impulsos que dão início ao processo de aprendizagem, podendo ocorrer na forma de percepção, transmissão, experiência, imitação, atividade, participação etc. Ela serve à integração pessoal em comunidades e na sociedade e, assim, também constrói a socialidade do indivíduo. Todavia, essa construção ocorre necessariamente por meio das duas outras dimensões.

Com base nas três dimensões referidas acima, nosso problema de pesquisa foi redefinido na forma de três questões gerais:

I. Quais saberes foram construídos pelos sujeitos?

II. Por que os sujeitos construíram tais saberes?

III. Como os sujeitos construíram tais saberes?

Como podemos ver essas três questões correspondem às três dimensões da aprendizagem de Illeris: I. Diz respeito à dimensão do conteúdo; II. À dimensão do incentivo; III. À dimensão da interação.

\section{Metodologia e apresentação dos dados}

Foram realizadas duas tomadas de dados, ambas no ano de 2011. As tomadas faziam parte das atividades da disciplina de um Programa de Pós-Graduação em Ensino de Ciências e Matemática ${ }^{6}$, que trata do aprendizado em ambientes fora da escola (educação não formal e/ou informal).

As tomadas de dados foram realizadas por meio de entrevistas semiestruturadas. Da primeira delas participaram cinco trabalhadores da construção civil no exercício de sua função, os quais possuíam de quinze a quarenta e seis anos de profissão, com escolaridade variando entre o $5^{\circ}$ ano do ensino fundamental (antiga $4^{\text {a }}$ série do primário) e o ensino médio completo. Na segunda tomada de dados os sujeitos das pesquisas foram dois técnicos em conserto de refrigeradores: o primeiro tinha feito curso técnico de eletroeletrônica industrial, com vinte anos de profissão; o segundo havia concluído o $9^{\circ}$ ano do ensino fundamental (antiga $8^{\text {a }}$ série) e tinha vinte e cinco anos de profissão. A maioria das entrevistas foi concedida no próprio local de trabalho. Em todas as tomadas de dados havia uma questão principal - o que você aprendeu ои aprende com/no seu trabalho? - que o entrevistador mantinha em mente, a partir da qual as demais questões iam sendo colocadas em função da necessidade. Acreditamos que, neste momento, não há razões para descrever todas essas questões, que sofreram muita variação em virtude dos diferentes profissionais e contextos envolvidos.

Os trabalhadores da construção civil serão nomeados como TCC 1, TCC 2 etc., enquanto que os técnicos em conserto de refrigeradores por TCR 1 e TCR 2. As falas serão apresentadas numeradas, para que possam ser recuperadas posteriormente, nas análises. Depois

\footnotetext{
${ }^{6}$ Programa de Pós-Graduação em Ensino de Ciências e Educação Matemática da Universidade Estadual de Londrina - PR. <http://www.uel.br/pos/mecem/>. Acesso em: 03 abril 2015.
} 
da fala segue a indicação, entre colchetes, do entrevistado a que ela pertence. Algumas frases são antecedidas pela letra $P$, elas são perguntas ou afirmações feitas pelos pesquisadores.

Os procedimentos metodológicos dessa pesquisa foram baseados na Análise Textual Discursiva (ATD), um procedimento analítico que se situa entre a análise de conteúdo e a análise de discurso. $\mathrm{Na}$ análise de conteúdo, procura-se 'o que' foi falado. Na análise do discurso, procura-se 'como foi falado'. Entre 'o que' e o 'como', tem-se a ATD, proposta pelo pesquisador Moraes (2003, p. 191), para quem, na análise textual, não se ambiciona avaliar "hipóteses para comprová-las ou refutá-las ao final da pesquisa; a intenção é a compreensão". $\mathrm{O}$ autor organiza os argumentos da ATD em torno de quatro aspectos: desmontagem dos textos - unitarização; o estabelecimento de relações - categorização; captando o novo emergente - emergência de uma compreensão renovada do todo; um processo auto-organizado que corresponde ao ciclo de análise descrito, do qual emergem novas compreensões.

Lançando mão de tais procedimentos, procuramos agrupar as unidades de análise segundo as três questões da pesquisa, já enunciadas, tomadas como categorias gerais. A seguir apresentamos os dados, separados segundo essas três categorias.

\section{Quais saberes foram construídos pelos sujeitos?}

Da análise geral das sete entrevistas, depreende-se que os saberes que os trabalhadores aqui considerados desenvolveram estão diretamente ligados à resolução dos problemas práticos enfrentados no dia a dia de cada uma das profissões.

No caso dos trabalhadores da construção civil, um dos problemas frequentes que eles têm para resolver é o de encontrar um ângulo reto, para erguer duas paredes na vertical ou para ver se um "cômodo está no esquadro". O procedimento é relatado abaixo:

1. Nós temos um segmento em construção civil, que eu não sei qual louco que inventou isso, mas existe um cálculo que você usa que é o seguinte: pra você achar o esquadro - que é deixar no esquadro que a gente fala -, você pega daqui aqui 80 centímetros certo? Você pega daqui aqui [desenhando no papel o que estava querendo representar] 60 centímetros, esse ponto desse ponto tem que dar 1 metro. Agora você não me pergunta quem foi que inventou isso aí que eu não sei. [TCC 1]

2. P: E como faz para saber se está mesmo no esquadro?

3. Vamos supor, você põe essa medida e se não der 1 metro você vai fechando até dar 1 metro. Daí você sabe que esses 80 centímetros estão retos e que esses 60 centímetros também. Depois se você puser um esquadro aqui ele vai dar um ângulo reto que é a parede reta. Faz o mesmo esquema nos quatro cantos. [TCC 1]

Outras operações matemáticas que os trabalhadores da construção civil precisam realizar com frequência são os cálculos de volume (“cubicar”) e cálculos de área de materiais diversos (como areia) e o cálculo da quantidade de tijolos que devem ser usados em uma construção:

4. P: na sua profissão o senhor usa a Matemática? 
5. [...] [Quando] a gente tem que cubicar um caminhão de areia, a gente conta quantos metros de areia tem no caminhão. Tem que aterrar uma coisa, tem que saber quantos metros de terra vai ali dentro daquele quadradinho, o quadrado vezes a altura dele, você tem que cubicar tudo aquilo. A gente usa mais na prática do que no conhecimento. [TCC 3]

6. P: no que o senhor usa o metro quadrado?

7. Para fazer essa calçada, eu multiplico o comprimento pela largura para dar o total do metro quadrado que tem. A gente vai calcular o material, a mão de obra pelo metro quadrado. Para cobrar, para fazer o orçamento do material, tem que saber o metro quadrado, você tem que usar a Matemática, não tem como você não usar a Matemática. [TCC 4]

8. P: quantos tijolos o senhor usa por metro quadrado?

9. É 35 tijolos por metro quadrado se for tijolo em pé e tijolo de seis furos. Se for (tijolo) deitado é 50 por metro quadrado. Deitado é quando quer uma parede dupla, porque ele (o tijolo) é deitado (dai é uma parede mais resistente). Geralmente a gente faz com tijolo deitado. De pé é mais por dentro da casa. [TCC 4]

No caso dos técnicos em refrigeração, embora a relação estabelecida com os conhecimentos científicos seja semelhante às estabelecidas pelos trabalhadores da construção civil em alguns aspectos (por exemplo, decorrem unicamente do trabalho), foi possível notar algumas diferenças. Os técnicos enfrentam cotidianamente a tarefa de resolver problemas de funcionamento das máquinas, tendo de utilizar frequentemente o processo de raciocínio lógico sobre as evidências (formulação de hipóteses, teste das mesmas etc.):

10. Só na experiência [para descobrir um problema de funcionamento]. Só na prática, que você vai testando. [...] Eu tinha uma máquina de gelo aqui, eu vou te dar uma ideia melhor. Vem aqui! Bom, do refrigerador no caso você já deu para ter mais ou menos uma noção, não? O porquê. Quando não gela não é só porque está faltando gás. Vamos identificar por que, são vários itens. Que nem, a câmara fria, ela trabalha com uma válvula reversora igual a essa. Quando ela precisa fazer o degelo, isso aqui, ele inverte a posição do gás. Em vez de ela gelar aqui, ela vai esquentar e gelar atrás. Quando você precisa, aqui bloqueou de gelo. Então eu preciso passar um gás quente aqui. Aí ele vai inverter. A câmara fria você não tem a resistência, que nem eu falei pra você, que faz o degelo. Ela tem essa válvula reversora com válvulas de pressão, com timer temporário para fazer a inversão da válvula reversora. [TCR 1]

Vemos que os saberes apresentados pelos entrevistados estão diretamente ligados à prática e foram construídos para solucionar os problemas que enfrentam no dia a dia. Embora tais saberes mantenham alguma relação com os conhecimentos científicos, os entrevistados demonstraram que esses últimos apresentam pouco ou nenhum valor para eles.

\section{Por que os sujeitos construíram tais saberes?}

Como nosso objetivo é entender a aprendizagem científica, a categoria II considera apenas a relação dos trabalhadores com o conhecimento científico específico envolvido em 
seu campo de trabalho. Não estaremos preocupados, portanto, com outros conhecimentos e saberes envolvidos ou com os interesses e motivações gerais que os levaram a optar por esses trabalhos.

No caso dos trabalhadores da construção civil, o conhecimento específico que aparece com mais evidência é a Matemática, como vimos. As relações dos TCC com esse conteúdo quase sempre estão diretamente vinculadas ao trabalho:

11. A Matemática pra mim é princípio de tudo, pra tudo que eu faço. [TCC 1]

12. Tudo aqui [na construção] depende de medida, de prumo, de esquadro... Não tem como fazer isso aqui sem tirar o nível, sem medir. Uma escora que você cortar depende de medida... Uma tábua que você vai precisar, tudo precisa de medida. [TCC 2]

13. Olha, mesmo sem querer a gente tá sempre usando, sem notar a gente usa direto a Matemática. Porque a gente faz conta de metro quadrado, conta de centímetro, até conta que eu nunca aprendi na escola a gente usa aqui, que é cubicar. [TCC 3]

14. P: É possível uma pessoa tornar-se pedreiro sem "gostar" [usar] da Matemática?

15. Impossível, porque se o pedreiro não usar o cálculo que é a Matemática ele não consegue trabalho. Só se ele for ajudante para bater massa. [TCC 1]

Para os técnicos em consertos de refrigeradores, o conhecimento que importa mais é relativo à Física:

16. Porque pra eu instalar um compressor num refrigerador, tem que ter a Física, porque eu tenho que saber amperagem do motor, wattagem ${ }^{7}$ do motor, voltagem do motor, a quantidade de gás que eu coloco. [...] tudo encaixa na Física. Tudo são cálculos, tanto o refrigerador num geral, a geladeira e a câmara fria, a única coisa que vai modificar é o conteúdo, o tamanho. [TCR 1]

Os trabalhadores da construção civil, em geral, desconhecem o teorema de Pitágoras e outros conceitos matemáticos. Eles utilizam uma "matemática" cotidiana aprendida com os trabalhadores da construção mais experientes e utilizada para fins específicos de alguns procedimentos necessários para a construção civil. O mesmo vale para os técnicos em refrigeração:

17. P: O que você aprendeu de Física no seu ambiente de trabalho? No seu trabalho de conserto de geladeira?

18. Física? Para falar bem a real pra você eu não sei nem o que é Física, porque eu não cheguei ao ponto de estudar Física. Porque eu só terminei a oitava série. O que é, agora eu vou perguntar para você: O que é Física? Para eu poder entrar na conversa.

19. P: A parte elétrica, a parte de refrigeração...

\footnotetext{
${ }^{7}$ Há um equivoco na utilização da palavra "wattagem" pelo depoente, indicamos que neste momento ele se referia à potência do motor do refrigerador.
} 
20. Ah! Sim. Eu conheço isso como comando elétrico. Seria o quê? Seria a amperagem, a voltagem, tanto a voltagem ACV e DCV. DCV voltagem contínua, ACV voltagem alternada. [TCR 2]

Embora possam ter tido maior ou menor escolaridade, possam ter apenas uma vaga ideia ou gostar mais ou menos de Matemática ou de Física, esses conteúdos são vistos por todos eles como fundamentais no cotidiano da profissão, em geral, associados a procedimentos de medidas e a resolução de problemas práticos. Portanto, o interesse e o sentido do conhecimento científico parecem decorrer, pelo menos para os casos analisados, mais das necessidades provenientes do trabalho diário (motivação extrínseca) do que por razões mais pessoais (motivação intrínseca).

\section{Como os sujeitos construíram tais saberes?}

Vimos que os entrevistados apresentam saberes da Matemática e da Física, que são importantes para a resolução dos problemas cotidianos do seu trabalho. Tendo a maioria deles a escolarização primária e, além disso, afastados da escola há muitos anos, como esses trabalhadores aprenderam os saberes da Matemática e da Física mencionados?

21. Na realidade foi assim: meu pai me levava na construção civil, para ajudar, e dizia assim: fica aí para limpar alguma coisa e eu fui aprendendo. Eu via um pedreiro assentar um tijolo, eu via um marceneiro assentando uma porta, eu ia aprendendo. Tudo o que eu sei na construção civil eu fui aprendendo assim. Eu tenho a prática, se você colocar a teoria eu não sei fazer. [TCC 1]

22. Eu aprendi mais pela curiosidade. Mestre de obra, as pessoas falando, engenheiro. E quando eu não sabia, eu perguntava para um engenheiro. [TCC 2]

23. Eu aprendi com meu tio. Eu aprendi a marcar obra com meu tio, eu marcava obra junto com ele. [...] Marcar obra você tem que colocar o cavalete e marcar. Colocar as estacas, daí faz o quadrado, daí você marca os pontos. Daí que vem a Matemática. [TCC 5]

$\mathrm{Na}$ aprendizagem da profissão fica bem aparente, principalmente no caso dos trabalhadores da construção civil, a importância dos profissionais mais experientes. No caso dos técnicos, talvez por exigir mais especialização, pode haver um processo de capacitação e realização de cursos. Mas aprender pela "prática" ainda é o modo mais valorizado por eles:

24. Eu fiz eletroeletrônica industrial no SENAI. [...] A gente tenta pegar muita coisa teoricamente, porque ajuda muito. Mas não tem coisa melhor do que a prática. [TCC 1]

25. [...] nessa empresa que eu evoluí mais, porque eles dão curso, as outras empresas, foi mais na base do pegar para fazer. [...] tem lançamento vai um técnico, passa um tempo vai outro, vai pra Curitiba e faz (o curso). [TCR 2]

Das entrevistas pudemos observar que em ambos os casos os trabalhadores afirmaram a importância da "prática" para a construção dos saberes. Embora esse aprendizado pela prática, em especial no caso dos TCR, possa ser um processo individual de testar hipóteses que resolvam um problema específico gerado no trabalho, acreditamos que, pelo menos no 
início da aprendizagem, ele deve ser sempre assistido ou supervisionado por um trabalhador mais experiente. Trata-se, portanto, de um aprendizado que ocorre em uma comunidade de prática.

\section{Análises e considerações finais}

Com base nos dados apresentados na seção anterior, parece-nos interessante pensar a aprendizagem no trabalho a partir da perspectiva trazida pela teoria social da aprendizagem de Wenger. Esse autor considera, fundamentalmente, a aprendizagem como participação social, sendo que:

A participação, aqui, refere-se não apenas a situações locais de envolvimento em certas atividades e com certas pessoas, mas a um processo mais abrangente de ser participante ativo das práticas de comunidades sociais e construir identidades em relação a essas comunidades (WENGER, 2013, p. 248).

A teoria de Wenger procura integrar quatro componentes para caracterizar a participação social como um processo de aprendizagem, sintetizados na Fig. 1:

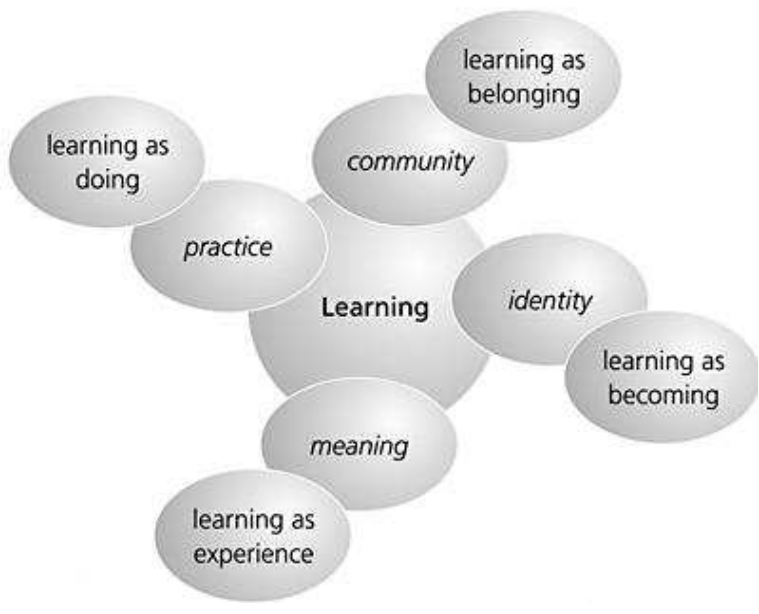

Fig. 1 -Quatro componentes da aprendizagem em Wenger.

Fonte: <http://pagi.wikidot.com/wenger-social-theory-learning>

Nesse sentido poderíamos entender a aprendizagem como: o pertencimento a uma comunidade, na qual nossa participação é reconhecida; como uma prática, uma ação social e histórica, compartilhada; como a capacidade de experimentar a vida e o mundo, individual e coletivamente, de forma significativa; e como um processo de tornar-se, de construir uma identidade em um processo pessoal e histórico (WENGER, 2013, p. 248-249).

Outro conceito que compõe a teoria de Wenger é o de comunidades de prática. Segundo ele, todos nós pertencemos a comunidades de prática, em casa, no trabalho, na escola, 
no lazer, em nossas vidas cotidianas. Elas são familiares e estão em toda parte, todavia são informais e não nomeadas. Além disso:

\begin{abstract}
[...] se considerarmos a nossa própria vida por essa perspectiva durante um momento, todos poderemos construir um quadro bastante bom das comunidades de prática a que pertencemos atualmente, aquelas a que pertencemos no passado e aquelas a que gostaríamos de pertencer no futuro. Também temos uma ideia muito boa de quem pertence a nossas comunidades de prática e por que, embora a participação raramente seja explicitada em uma lista de membros ou de critérios de qualificação. Além disso, provavelmente, podemos distinguir umas poucas comunidades de prática das quais somos membros importantes de um número maior de comunidades nas quais temos um tipo mais periférico de participação (WENGER, 2013, p. 250-251).
\end{abstract}

Com base na teoria de Wenger, podemos concluir que as falas dos sujeitos da pesquisa incidiram principalmente sobre três dos componentes da aprendizagem indicadas na Fig. 1: o pertencimento a uma comunidade; a relação estreita com um fazer, uma prática; e a natureza significativa da experiência de aprendizado. Com relação à componente identidade, ela apareceu claramente apenas na fala de um dos entrevistados:

26. Queira ou não queira a gente é um artista. Uma mulher falou pra mim que eu sou um artista, só que ninguém reconhece. Ô, fazer um trabalho desse aqui, grande, uma casa. É lógico, tem o engenheiro que desenha, mas a gente que tem que ir lá, decifrar tudo, montar, então na verdade, se você colocar, a gente faz um trabalho de artista, não é verdade? O pintor, por exemplo, não pinta lá o seu quadro? Então, nós que fazemos a casa. Você olha uma profissão dessa, olha que maravilha. Quer dizer então, hoje eu tive o entendimento que a gente é o artista, não tem valor, mas somos o artista, pode ter certeza disso. [TCC 4]

É evidente também, por outro lado, que a elaboração dos saberes do trabalho pode ser pensada de maneira análoga à elaboração dos saberes docentes. Em virtude disso, dada a semelhança entre os saberes construídos pelos trabalhadores aqui analisados e os saberes docentes, conforme descrito por Tardif, vamos lançar mão de um artifício, já utilizado por nós em outro artigo (ARRUDA; PASSOS, 2012), que consiste em operar um espelhamento com relação ao pensamento desse autor, de tal forma a traduzir algumas de suas frases para o contexto da pesquisa aqui apresentada. Com isso é possível construir um quadro de equivalência entre os saberes docentes e os saberes do trabalho, como a apresentada no Quadro 1. Essa equivalência iluminará mais a natureza dos saberes do trabalho, como veremos.

Nessa operação de espelhamento, procuramos substituir em algumas frases escolhidas de Tardif a palavra docente pela palavra trabalhador. Não estamos querendo com isso diferenciar o docente ou o professor de um trabalhador, mas, ao contrário, tornar evidente que os professores formam um subconjunto do conjunto mais geral da classe de trabalhadores. $\mathrm{Ou}$ seja, a operação proposta apenas procura generalizar as frases de Tardif para todos os traba- 
lhadores para os quais valeriam os pressupostos assumidos por Tardif para os saberes docentes, por exemplo, trabalhadores da construção civil, técnicos em consertos de refrigeradores, mecânicos, médicos etc.

Quadro 1 - equivalência entre os saberes docentes e os saberes do trabalho

\begin{tabular}{|c|c|c|}
\hline $\begin{array}{l}\text { Tardif, } \\
\text { 2002, } \\
\text { páginas }\end{array}$ & Saberes docentes & Saberes do trabalho \\
\hline 15 & $\begin{array}{l}\text { O saber dos professores não é o "foro } \\
\text { íntimo" povoado de representações } \\
\text { mentais, mas um saber: sempre ligado a } \\
\text { uma situação de trabalho com outros } \\
\text { (alunos, colegas, pais etc.); um saber } \\
\text { ancorado numa tarefa complexa } \\
\text { (ensinar); situado num espaço de } \\
\text { trabalho (a sala de aula, a escola); } \\
\text { enraizado numa instituição e numa } \\
\text { sociedade. }\end{array}$ & $\begin{array}{l}\text { O saber dos trabalhadores não é o "foro } \\
\text { íntimo" povoado de representações mentais, } \\
\text { mas um saber: sempre ligado a uma situação } \\
\text { de trabalho com outros (parentes, } \\
\text { trabalhadores mais experientes etc.); um } \\
\text { saber ancorado numa tarefa complexa } \\
\text { (construir uma casa, um prédio, consertar } \\
\text { um refrigerador, uma câmara fria etc.); } \\
\text { situado num espaço de trabalho (a } \\
\text { construção, a oficina, uma residência); } \\
\text { enraizado numa comunidade. }\end{array}$ \\
\hline 36 & $\begin{array}{l}\text { Pode-se definir o saber docente como } \\
\text { um saber plural, formado pelo } \\
\text { amálgama, mais ou menos coerente, de } \\
\text { saberes oriundos da formação } \\
\text { profissional e de saberes disciplinares, } \\
\text { curriculares e experienciais. }\end{array}$ & $\begin{array}{l}\text { Pode-se definir o saber do trabalho como um } \\
\text { saber plural, formado pelo amálgama, mais } \\
\text { ou menos coerente, de saberes oriundos da } \\
\text { formação profissional (quando ela existe) e } \\
\text { de saberes experienciais. }\end{array}$ \\
\hline 48 & $\begin{array}{l}\text { Pode-se chamar de saberes experienciais } \\
\text { o conjunto de saberes atualizados, } \\
\text { adquiridos e necessários no âmbito da } \\
\text { prática da profissão docente e que não } \\
\text { provêm das instituições de formação } \\
\text { nem dos currículos. Estes saberes não se } \\
\text { encontram sistematizados em doutrinas } \\
\text { ou teorias. }\end{array}$ & $\begin{array}{l}\text { Pode-se chamar de saberes experienciais o } \\
\text { conjunto de saberes atualizados, adquiridos } \\
\text { e necessários no âmbito da prática da } \\
\text { profissão e que não provêm das instituições } \\
\text { de formação. Estes saberes não se } \\
\text { encontram sistematizados em doutrinas ou } \\
\text { teorias. }\end{array}$ \\
\hline 49 & $\begin{array}{l}\text { [os saberes experienciais] São saberes } \\
\text { práticos (e não da prática: eles não se } \\
\text { superpõem à prática para melhor } \\
\text { conhecê-la, mas se integram a ela e dela } \\
\text { são partes constituintes enquanto prática } \\
\text { docente) e formam um conjunto de } \\
\text { representações a partir das quais os } \\
\text { professores interpretam, compreendem e } \\
\text { orientam sua profissão e sua prática } \\
\text { cotidiana em todas as suas dimensões. }\end{array}$ & $\begin{array}{l}\text { [os saberes experienciais] São saberes } \\
\text { práticos (e não da prática: eles não se } \\
\text { superpõem à prática para melhor conhecê-la, } \\
\text { mas se integram a ela e dela são partes } \\
\text { constituintes enquanto prática do trabalho) e } \\
\text { formam um conjunto de representações a } \\
\text { partir das quais os trabalhadores interpretam, } \\
\text { compreendem e orientam sua profissão e sua } \\
\text { prática cotidiana em todas as suas } \\
\text { dimensões. }\end{array}$ \\
\hline
\end{tabular}

Fonte: Os autores.

Cremos que o Quadro 1 pode nos ajudar a entender melhor a natureza dos saberes construídos pelos trabalhadores, analisados nesse artigo. Nesse sentido seria possível afirmar que os saberes docentes são um caso particular dos saberes do trabalho, quando estamos tratando com uma classe particular de trabalhadores que são os professores. 
Retomemos as três questões de pesquisa:

I. Quais saberes foram construídos pelos sujeitos?

II. Por que os sujeitos construíram tais saberes?

III. Como os sujeitos construíram tais saberes?

As respostas para essas questões tornam-se agora simples: os saberes construídos pelos sujeitos são análogos aos saberes experienciais de Tardif, constituídos como um conjunto de representações a partir das quais eles interpretam, compreendem e resolvem os problemas de sua prática cotidiana [falas $1,3,5,7,9,10]$; tais saberes foram construídos porque são úteis e necessários para a prática da profissão [11, 12, 13, 15, 16, 20]; a aprendizagem de tais saberes se deu principalmente com o auxílio dos colegas mais experientes da comunidade de que faziam parte $[21,22,23,24,25]$. Provavelmente, isso vale para todos os trabalhadores, cujos trabalhos e configurações onde eles ocorrem sejam de natureza semelhante às dos sujeitos desta pesquisa.

\section{Referências}

ALHEIT, P.; DALSIEN, B. Processo de formação e aprendizagens ao longo da vida. Educação e Pesquisa, São Paulo, v. 32, n. 1, p. 177-197, 2006.

ASPIN, D. N.; CHAPMAN, J. D. Lifelong learning: concepts and conceptions. In: ASPIN, N. D. Philosophical Perspectives on Lifelong Learning. Lifelong Learning Book Series, Springer, v. 11, p. 19-38, 2010.

ALVES, D. R. S.; PASSOS, M. M.; ARRUDA, S. M. A educação não formal em periódicos da área de Ensino de Ciências no Brasil (1979-2008). Revista Brasileira de Ensino de Ciência e Tecnologia - RBECT, v. 3, p. 16-40, 2010.

ARRUDA, S. de M.; PASSOS, M. M. Da psicanálise ao ensino de ciências: o "desejo do docente" e o "professor como um lugar". Ciência \& Educação, v. 18, p. 69-80, 2012.

ARRUDA, S. M.; PASSOS, M. M.; PIZA, C. A. M.; FELIX, R. A. B.. O aprendizado científico no cotidiano. Ciência \& Educação, v. 19, p. 481-498, 2013.

BAGNALL, R. J. Lifelong education: the institutionalization of an illiberal and regressive ideology? Education Philosophy and Theory, v. 22, p. 1-7, 1990.

BILLETT, S. Learning in the workplace: strategies for effective practice. Austrália: Allen \& Unwin, 2001.

DIERKING, L. D. Lessons without limit: how free-choice learning is transforming science and technology education. História, Ciências, Saúde - Manguinhos, v. 12 (supplement), p. 145-160, 2005. 
EUROPEAN COMMISSION. Directorate-General for Education and Culture. Making a European area of lifelong learning a reality. Brussels, 2001. Disponível em: <http://www.bologna-berlin2003.de/pdf/MitteilungEng.pdf>. Acesso em: 28 jul. 2013.

HYLAND, T. Lifelong learning and vocational education and training: values, social capital and caring in work-based learning provision. In: ASPIN, N. D. Philosophical Perspectives on Lifelong Learning. Lifelong Learning Book Series, Springer, v. 11, p. 57-69, 2010.

ILLERIS, K (Org.). Uma compreensão abrangente sobre a aprendizagem humana. In: Teorias contemporâneas da aprendizagem. Porto Alegre: Penso, p. 15-30, 2013.

MORAES, R. Uma tempestade de luz: a compreensão possibilitada pela análise textual discursiva. Ciência \& Educação, Bauru, v. 9, n. 2, p. 191-211, 2003.

NATIONAL RESEARCH COUNCIL. Learning science in informal environments: people, places, and pursuits. Committee on learning science in informal environments. Philip Bell, Bruce Lewenstein, Andrew W. Shouse, and Michael A. Feder (Eds.). Board on science education, center for education. Division of behavioral and social sciences and education. Washington, DC: The National Academies Press, 2009.

Taking science to school: learning and teaching science in grades K-8. Washington: National Academies Press, 2007.

TARDIF, M. Saberes docentes e formação profissional. Petrópolis: Vozes, 2002.

VERONA, M. F.; MORI, H.; ARRUDA, S. de M. Raízes formais e informais da opção pelo curso de Ciências Biológicas. Ensaio - Pesquisa em Educação em Ciências, v. 10, p. 1-20, 2008.

WENGER, E. Uma teoria social da aprendizagem. In: ILLERIS, Knud (Org.). Teorias contemporâneas da aprendizagem. Porto Alegre: Penso, p. 246-257, 2013. 